\title{
COMPARISON OF POSTERIOR RESIDUAL RIDGE RESORPTION IN PATIENTS WEARING CONVENTIONAL DENTURE, TWO IMPLANT- RETAINED MANDIBULAR OVERDENTURE AND FOUR IMPLANT- SUPPORTED OVERDENTURE: A 5-YEAR RETROSPECTIVE STUDY
}

\author{
Gilan Youssef Altonbary*
}

\begin{abstract}
Purpose: The aim of the following study was to assess and compare the effect of treatment with conventional complete dentures, two implant retained mandibular overdenture and four implant supported mandibular overdenture on mandibular posterior residual ridge resorption over a 5-year period.
\end{abstract}

Material and methods 24 patients were selected from previous studies, where (group I) included 8 patients previously treated with conventional complete dentures. The second group (group II) 8 patients received mandibular overdenture using two osseointegrated implants, (group III) 8 patients received implant supported mandibular overdenture using two implants in canine region and two implants in the first molar region connected with rigid bar. Posterior residual ridge resorption was evaluated for all groups using proportional area measurements.

Results: After 5years of prosthetic treatment, regarding posterior residual ridge resorption, statistically significant bone resorption had occurred for all the three groups, also statistically significant difference was reported when comparing the two-implant overdenture group to the fourimplant supported overdenture group.

Conclusion Four implant supported overdenture with the posterior implants in the first molar region showed the least amount of posterior ridge resorption after 5 years of treatment in comparison to conventional complete dentures or two implant retained overdenture.

KEYWORDS: Ridge resorption, complete denture, implant overdenture

\section{INTRODUCTION}

The main objective of prosthodontic treatment is the conservation of remaining structures. However, a phase of remodeling occurs safter natural teeth extraction, which generally ended with some loss in the residual ridge height. Although ridge atrophy might not interfere with the target of placement of implants, a residual ridge with acceptable

\footnotetext{
* Assistant Professor, Removable Prosthodontics Department, Faculty of Dentistry, Mansoura University. Mansoura. Egypt.
} 
dimensions is more advantageous for the success of treatment with implant overdentures.

Major individual variations in the amount of residual ridge resorption were reported between patients and even at different times and location of the same patient. ${ }^{1}$ patient wearing conventional denture often encounter problems as poor stability and retention of the denture associated with reduced chewing performance. Implant-retained overdenture is a treatment modality that was first introduced by Batenburg et al, it could enhance oral function, biting force and comfort. ${ }^{2,3,4}$ Even though implantretained overdenture as a treatment modality had been examined meticulously in many articles, furthermost of the studies had mainly focused on the consequence of the use of two implant retained mandibular overdenture, Lechner and Mammen ${ }^{5}$ reported maxillary denture looseness, loss of occlusion in the posterior region, increase in anterior occlusal pressure and bone resorption in the anterior part of maxilla, alike to the effects reported in 'combination syndrome' when patients receive mandibular bar retained overdentures using two implants opposing maxillary dentures. In these states, implants somewhat encourage the patients to function anteriorly with maximum bite force similar to that occurred with natural dentition ${ }^{6}$, to avoid this, the placement of implants posteriorly and use a fourimplant supported mandibular overdenture could be a better treatment option, the aim of this study was to evaluate and compare the effect of treatment with conventional complete dentures, two implant retained mandibular overdenture and four implant supported mandibular overdenture on mandibular posterior residual ridge resorption after 5 years. The research hypothesis was that patients rehabilitated with mandibular overdentures assisted by 4 implants; two implants in the canine regions and two implants in the first molar regions offered a lesser amount of resorption of the posterior mandibular ridge when compared to using conventional dentures or two implant retained mandibular overdenture.

\section{MATERIALS AND METHODS}

\section{Patient selection}

For the present study, panoramic radiographs that were obtained before and 5 years after the prosthetic treatment for patients that were previously enrolled in other studies. The studies were carried out by the department of removable prosthodontics, faculty of dentistry, Mansoura University, Egypt and involved 24 patients, where (group I) included 8 patients previously treated with conventional mandibular dentures opposing maxillary complete dentures. The second group (group II) 8 patients received a mandibular-overdenture utilizing two osseointegrated implants (Dyna) with dimensions $15 \mathrm{~mm} \times 3.6 \mathrm{~mm}$ in canine regions, retained with bar attachment and a maxillary complete denture, for the third group (group III) 8 patients were treated with implant supported mandibular overdenture utilizing two osseointegrated implants previously inserted in the edentulous mandible with dimensions $15 \mathrm{~mm} \times 3.6 \mathrm{~mm}$ in canine regions and two implants $13 \mathrm{~mm} \times 4.2 \mathrm{~mm}$ in first molar regions utilizing standardized 2- stage submerged surgical protocol in a previous study. The four implants were connected with a rigid bar attachment retaining the mandibular overdenture. All patients were carefully chosen with the following criteria; history of poor retention and stability of conventional denture, bone height between 8 and $25 \mathrm{~mm}$ guided by lateral cephalometries, with history of no previous surgery and no contraindications for surgical procedures. All patients were informed about all the study procedures and signed a consent.

\section{Clinical evaluat ion}

Posterior residual ridge resorption was evaluated for all groups according to the method that used by Wright et al. ${ }^{7}$ and kordatzis et al $2003^{1}$, it consisted of proportional area measurements, using proportions minimized magnification errors. For 
each radiograph, a tracing was done on the mandible. On tomograms done previous to treatment and 5 years after, proportional area measurements were made on for the posterior mandibular ridge. An area was confined by a line connecting the gonion to the crest of the residual ridge and lowest point of the mental foramen then stated as a proportion of an area that is not reliant on the ridge. The concept of using proportions instead of definite measurements reduced magnification and distortion errors. Figure 1 and 2 showed the anatomical landmarks traced and outlined. The experimental bone area was highlighted as area PAMG and the reference area as triangle MGN (Fig. 2). The bone area was divided by the reference area to generate a ratio. The ratios were averaged for both right and left side of each patient. The ratio at 0 years was subtracted from the that at 5 years to calculate the change in posterior mandibular residual ridge resorption and indicated as PM and RR.

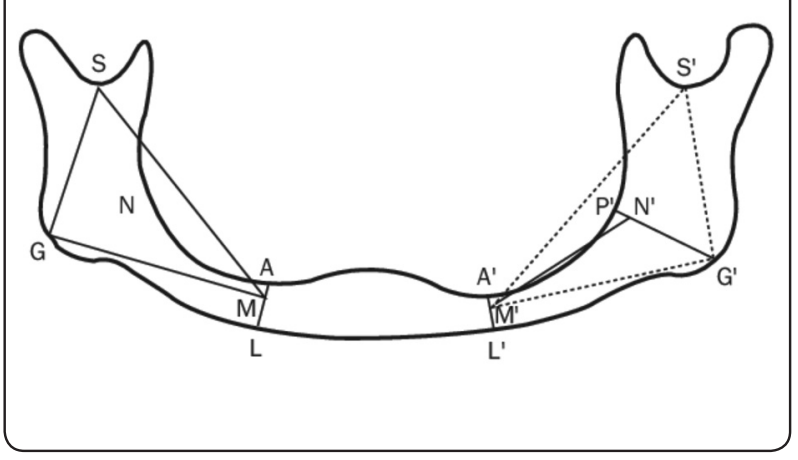

Fig. (1) Anatomical landmarks M, M' (lower border of mental foramen); S, S' (Sigmoid notch); G, G' (gonion) were used to form triangles M-S-G and M'-S'-G' with centres $\mathrm{N}$ and $\mathrm{N}^{\prime}$, respectively. Border lines were outlined as following: M-G and M'-G', A-L and A'$\mathrm{L}^{\prime}$ (crest of residual ridge to lower border of mandible perpendicular to $M-G$ and $\left.M^{\prime}-G^{\prime}\right), M-N$ and $M^{\prime}-N^{\prime}$, and G-P and G'-P' (G-N and G'-N' prolonged to crest of the ridge at $\mathrm{P}$ and $\left.\mathrm{P}^{\prime}\right)$.

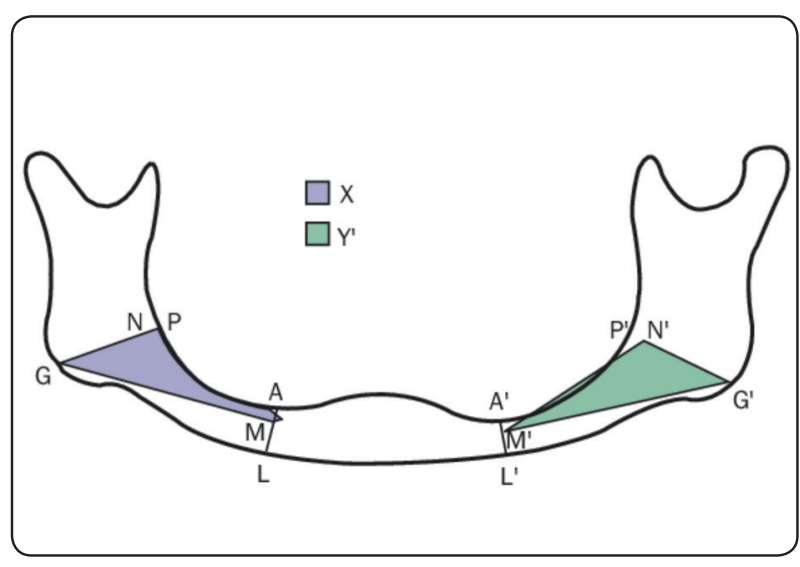

Fig. (2) Areas were defined as following: $X$ and $X^{\prime}$ by the crest of the residual P-A and $\mathrm{P}^{\prime}-\mathrm{A}^{\prime}$ and the border lines A-M and A'-M', M-G and M'-G', and G-P and G'-P', respectively; and $\mathrm{Y}$ and $\mathrm{Y}^{\prime}$ by the triangles $\mathrm{M}-\mathrm{G}-\mathrm{N}$ and $\mathrm{M}^{\prime}-\mathrm{G}^{\prime}-\mathrm{N}$ ', respectively. Posterior area index was estimated from $\mathrm{X} / \mathrm{Y}+\mathrm{X}^{\prime} / \mathrm{Y}^{\prime}$.

\section{Statistical Analysis}

Data were imported to IBM SPSS software package version 20.0. (Armonk, NY: IBM Corp). The Kolmogorov-Smirnov test was utilized for verification of normality of distribution. Quantitative data were demarcated utilizing range (minimum and maximum), mean, standard deviation. The obtained results were considered significant at the 5\% level. F-test (ANOVA) was utilized with normally distributed quantitative variables, for comparison between more than two groups, pairwise comparisons were done by Post Hoc test (Tukey)

\section{RESULTS}

Significant resorption was noted between 0 and 5 years for all the three groups as showed in (Table 1). Statistically significant difference was reported for the conventional complete denture group compared to either the two-implant overdenture group or the four-implant supported overdenture group, also statistically significant difference was reported when comparing the two-implant overdenture group to the four-implant supported overdenture group. 
TABLE (1) Comparison between mandibular posterior ridge resorption between the three groups.

\begin{tabular}{|l|c|c|c|}
\hline & Mean & SD & Min-Max \\
\hline Group I & 1.20 & \pm 0.08 & $1.10-1.30$ \\
\hline Group II & 0.68 & \pm 0.07 & $0.60-0.80$ \\
\hline Group III & 0.36 & \pm 0.09 & $0.20-0.50$ \\
\hline P & $<0.001^{*}$ \\
\hline $\begin{array}{l}\text { Sig. bet. } \\
\text { groups. }\end{array}$ & $\mathrm{p}_{1}<0.001^{*}, \mathrm{p}_{2}<0.001^{*} \mathrm{p}_{3}<0.001^{*}$ \\
\hline
\end{tabular}

SD: Standard deviation

F: F for ANOVA test, Pairwise comparison bet. each 2 groups was done using Post Hoc Test, (Tukey)

p: $p$ value for comparing between the studied groups

p1: $p$ value for comparing between group 1 and group 2

p2: p value for comparing between group 1 and group 3

p3: $p$ value for comparing between group 2 and group 3

*: Statistically significant at $p \leq 0.05$.

\section{DISCUSSION}

Considering posterior mandibular residual ridge resorption, the methodology utilized for radiographic evaluation in this study was first introduced by Wilding and coworkers, it was also reported in other studies. ${ }^{1,8,9}$.

In the present study, posterior residual ridge resorption was observed for the three groups. Significant difference was reported between the complete denture group when compared to both implant overdenture groups. Posterior residual ridge resorption was reported in both overdenture groups, occlusal load and forces induced on either conventional dentures or implant overdenture designs could be the main prompting factor for bone resorption ${ }^{10}$. To explain this, the loading patterns should be considered. However, the use of four implants with two posterior implants in the first molar region has reported the minimal amount of posterior ridge resorption after 5 years. With implant overdentures, especially with vertically oriented implants, stresses generated tend to be lower and evenly distributed around the implants. ${ }^{11}$ From the biomechanical point of view, bone adjacent to the implant sites could be more favorable ${ }^{12,13}$.

It is expected that reduced rate of bone resorption with implant- overdenture groups could be explained by the less unfavorable bone loading adjacent to implants thus residual posterior ridge protection from unnecessary loading, also this load is inversely proportional with the distance from the implant. A study by Sennerby and coworkers, 14 agreed with these findings, they reported minimal bone resorption adjacent to implant sites. They utilized linear measurements at standard sites and area measurements, on cephalometries, they reported statistically significant residual ridge resorption for complete denture wearers, while small insignificant changes posterior to the most distal implant for implant overdenture wearers. In another a study carried out by Tymstra et al, ${ }^{15}$ reported no significant differences between the groups, however, there appeared to be slightly more posterior residual ridge resorption in group rehabilitated with two implants when compared to patients rehabilitated with fours implants or a conventional denture.

\section{CONCLUSION}

Within this study limitations, residual ridge resorption in the mandibular posterior region was inevitable either on using implant-supported mandibular overdenture or a conventional mandibular denture. However, rehabilitation of edentulous patients with four implant supported overdentures with the posterior implants in the first molar region showed the least amount of posterior ridge resorption after 5 years of treatment in comparison to conventional complete dentures or two implant retained overdenture. 


\section{REFERENCES}

1. Kordatzis K, Wright PS, Meijer HJ. Posterior mandibular residual ridge resorption in patients with conventional dentures and implant overdentures. Int J Oral Maxillofac Implants. 2003;18(3):447-452.

2. Boerrigter EM, Stegenga B, Raghoebar GM, Boering G. Patient satisfaction and chewing ability with implant-retained mandibular overdentures: a comparison with new completedentures with or without preprosthetic surgery. J Oral Maxillofac Surg. 1995; 53:1167-1173.

3. Fontijn-Tekamp FA, Slagter AP, Van't Hof MA, Geertman ME, Kalk W. Bite forces with mandibular implant-retained overdentures. J Dent Res. 1998; 77:1832-1839.

4. Batenburg, R.H.K.,Meijer, H.J.A., Raghoebar, G.M.\& Vissink, A. (1998a) Treatment concept for mandibular overdentures supported by endosseous implants. A literature review. International Journal of Oral \& Maxillofacial Implants 13:539-545.

5. Lechner SK, Mammen A. Combination syndrome in relation to osseointegrated implant-supported overdentures: a survey. Int J Prosthodont. 1996; 9:58-64.

6. Thiel CP, Evans DB, Burnett RR. Combination syndrome associated with a mandibular implant-supported overdenture: a clinical report. J Prosthet Dent. 1996; 75:107-113.

7. Wright PS, Glantz PO, Randow K, Watson RM. The effects of fixed and removable implant-stabilised prostheses on posterior mandibular residual ridge resorption. Clin Oral Implants Res. 2002; 13:169-174.
8. Jacobs R, Schotte A, van Steenberghe D, Quirynen M, Naert I. Posterior jaw bone resorption in osseointegrated implant-supported overdentures. Clin Oral Implants Res 1992; 3:63-70.

9. Wilding RJC, Levin I, Pepper R. The use of panoramic xrays to measure bone areas. J Oral Rehabil 1987; 14:557-567.

10. Klemetti E. A review of residual ridge resorption and bone density. J Prosthet Dent. 1996;75(5):512-514.

11. Federic DR, Caputo AA. Effect of overdenture retention designs and implant orientations on load transfer characteristics. J Prosthet Dent 1996; 76:624-632.

12. Meijer HJA, Starmans FJM, Steen WHA. Location of implants in the interforaminal region of the mandible and the consequences for the design of the superstructure. J Oral Rehabil 1994; 21:47-56.

13. 13. Chao YL, Meijer HJA, van Oort RP, Veersteegh PAM. The incomprehensible success of the stabilized overdenture in the edentulous mandible: A literature review on transfer of chewing forces to bone surrounding implants. Eur J Prosthodont Restorative Dent 1995; 3:255-261.

14. Sennerby L, Carlsson G, Bergman B, Warfinge J. Mandibular bone resorption in patients treated with tissue integrated prostheses and in complete denture wearers. Acta Odontol Scand 1988; 46:135-140.

15. Tymstra N, Raghoebar GM, Vissink A, Meijer HJ. Maxillary anterior and mandibular posterior residual ridge resorption in patients wearing a mandibular implant-retained overdenture. J Oral Rehabil. 2011;38(7):509-516. 